\title{
Work-related allergy in medical doctors: atopy, exposure to domestic animals, eczema induced by common chemicals and membership of the surgical profession as potential risk factors
}

\author{
Hitomi Kanayama · Kazuhiro Sato • Tomio Mori • \\ Takayoshi Hirai · Tomohiro Umemura · Tarou Tamura • \\ Toshiko Ido • Masanobu Kumakiri · Yukinori Kusaka
}

Received: 18 January 2011 / Accepted: 1 July 2011 / Published online: 19 August 2011

(C) The Author(s) 2011. This article is published with open access at Springerlink.com

\begin{abstract}
Purpose To investigate the risk factors associated with work-related allergy-like symptoms in medical doctors.

Methods Self-administered questionnaire survey and CAP test were conducted among medical school students in the 4th grade of their 6-year medical course in 1993-1996 and 1999-2001. Follow-up questionnaires were sent in 2004 to the graduates. These questionnaires enquired into personal and family history of allergic diseases, lifestyle, history of allergy-like symptoms including work-relatedness and occupational history as medical doctors. Relationships between allergy-like symptoms and relevant factors were evaluated by multivariate logistic regression analysis.
\end{abstract}

Electronic supplementary material The online version of this article (doi:10.1007/s00420-011-0682-z) contains supplementary material, which is available to authorized users.

H. Kanayama $(\square) \cdot$ K. Sato $\cdot$ T. Hirai $\cdot$ T. Umemura $\cdot$

T. Tamura $\cdot$ Y. Kusaka

Department of Environmental Health,

Faculty of Medical Sciences, University of Fukui,

23-3 Matsuokashimoaizuki, Eiheiji-cho,

Yoshida-gun, Fukui 910-1193, Japan

e-mail: hitomikanayama@post.nifty.jp

T. Mori

Fukui Prefectural Institute of Public Health

and Environmental Science, 39-4, Harame-cho,

Fukui City, Fukui 910-8551, Japan

T. Ido $\cdot$ M. Kumakiri

Department of Dermatology, Faculty of Medical Sciences,

University of Fukui, 23-3 Matsuokashimoaizuki,

Eiheiji-cho, Yoshida-gun, Fukui 910-1193, Japan
Results Of 261 respondents at the follow-up survey, 139 $(53.3 \%)$ and $54(20.7 \%)$ had a history of any allergy-like symptoms and any work-related allergy-like symptoms, respectively. Female gender and family history of allergic diseases were significantly associated with any allergy-like symptoms. Personal history of allergic disease, exposure to domestic animals, eczema caused by rubber gloves, metallic accessories, or cosmetics during schooling days, and membership of the surgical profession were significant risk factors for work-related allergy-like symptoms. On the contrary, to work-related allergy-like symptoms, gender, age, and smoking status were not significantly related, and consumption of prepared foods was inversely related.

Conclusions Personal history of atopy and eczema induced by common goods and the history of keeping domestic animals may be predictors of work-related allergy-like symptoms in doctors. After graduation from medical school, physicians start with exposure to various allergens and irritants at work, which relate to work-related allergy-like symptoms, especially for surgeons.

Keywords Occupational allergy · Doctor · Dermatitis · Rhinitis · Asthma

\section{Introduction}

Work-related allergy is one of the important occupational health problems among medical doctors. At present, about 287,000 doctors work in Japan. The number of doctors per hundred thousand of the population in Japan is ranked low compared to other OECD member countries, and Japanese medical doctors must work excessively long hours. Decline of work efficiency and of QOL caused by work-related 
allergies is not only a personal problem but can also coNSntribute a substantially to loss of human resources for community health.

Allergic diseases have been increasing and are prevalent worldwide especially among children and young adults (Pearce et al. 1993; Ng and Tan 1994; Lundbäck 1998; Devereux 2006; Norbäck et al. 2007). On the other hand, the increase has reached a plateau in some developed countries (Ronchetti et al. 2001; Zöllner et al. 2005). However, allergic diseases are common and represent a considerable global health problem at present.

Health care workers are occupationally exposed to many chemical and organic substances causing allergic diseases in the hospitals, clinics, and laboratories (Pechter et al. 2005; Delclos et al. 2007). For the last few decades, latex allergy have been a major occupational health concern in the hospital environment (Lagier et al. 1992; Vandenplas et al. 1995; Crippa and Pasolini 1997; Liss et al. 1997; Leung et al. 1997; Larese Firon et al. 2001; Nettis et al. 2002; Verna et al. 2003; Filon and Radman 2006). In addition, chemical substances like disinfectants, aerosolised medications, adhesive solvents, and cleaning products have been identified as risk factors associated with allergy among nurses, nursing-related professionals (Mirabelli et al. 2007; Arif et al. 2009), and health care workers including medical doctors (Delclos et al. 2007). Workrelated allergies among health care workers may bring about not only decline in work efficiency and QOL, but also serious adverse consequences to the affected workers (Kujala et al. 1997). Personal history of allergic diseases is also known to be associated with an increase in work-related allergies (Fuortes et al. 1996; Sato et al. 2004; Filon and Radman 2006).

Despite the great variety of allergens in hospital and laboratory environments, as far as we know, there are few such studies on medical students' (Taylor and Broom 1981; Ogino et al. 1990; Leggat and Smith 2007), and work-related allergies among medical doctors are usually reported along with hospital workers. In Japan, to our knowledge, there had been no epidemiological study describing work-related allergies in the hospital environment until our 2004 study. This study (Sato et al. 2004) focused on the risk factors for work-related allergies among 895 doctors, using a cross-sectional mail questionnaire survey to demonstrate that personal history of allergic diseases and the profession as surgical doctors were significantly associated with work-related allergy.

The present study, ranging from 1993 to 2004, aimed to investigate predictive risk factors for work-related allergy, by conducting both a baseline questionnaire survey for medical students and a follow-up questionnaire survey for graduates, along with baseline CAP test.

\section{Methods and subjects}

\section{Questionnaire}

The self-administered questionnaire consisted of items based on the International Study of Asthma and Allergies in Childhood (ISAAC) questionnaire (ISAAC Co-ordinating Committee 1992) and our original items. The baseline and follow-up questionnaire used in our study are provided in the Appendix.

\section{Baseline questionnaire items}

Our questionnaire items included demographic information; physician-diagnosed personal history and family history of allergic diseases, including bronchial asthma (BA), allergic rhinitis and/or pollen allergy (AR/PA), sinusitis, eczema, urticaria, allergic conjunctivitis (AC), and atopic dermatitis (AD); and height and weight. In addition, we documented lifestyle, including smoking status, living environment before undertaking medical study, physical activity, eating habits, and hobbies as well as history of allergy-like symptoms. Questions on the history of allergylike symptoms were divided into four subsections: respiratory symptoms including wheezing and whistling, i.e. BA-like symptoms; dermal symptoms including reddish skin, itching, and oozing, i.e. AD, eczema, or urticaria-like symptoms; nasal symptoms including sneezing, nasal discharge, and nasal obstruction, i.e. AR/PA-like symptoms; and ocular symptoms including eye itching, reddish eyes, and watery eyes, i.e. AC or PA-like symptoms. Each subsection comprised a core question on the allergy-like symptom experienced ever and a series of branch questions on the age of first attack, changes in symptom severity, and season/months in which the symptoms most frequently appeared. Respiratory allergy-like symptoms, dermal allergy-like symptoms, nasal allergy-like symptoms, and ocular allergy-like symptoms were defined as presence if the core questions (VI.1.a, VI.2.a, VI.3.a, and VI.4.a, refer to appendix) were responded 'yes.' In addition, eczema caused by rubber gloves, metallic accessories, and cosmetics was documented and the respondents who replied 'yes' toward this were also considered to be the subjects with dermal symptoms.

\section{Follow-up questionnaire items}

This questionnaire consisted of demographic information, smoking status, history of allergy-like symptoms, and occupational history as a medical doctor. Similar to the baseline study, questions on the history of allergy-like symptoms were divided into four subsections. Each subsection consisted of a core question on the allergy-like symptom 
experienced ever and a series of branch questions. Respiratory allergy-like symptoms, dermal allergy-like symptoms, nasal allergy-like symptoms, and ocular allergy-like symptoms were defined as presence if the core questions (II.1.a, II.2.a, II.3.a, and II.4.a, refer to appendix) were responded 'yes.' The branch questions concerned changes in symptom severity after graduation, whether the symptoms seemed to be work-related, and appearance of the symptoms by workrelated items (chemical substances, medical tools, and medical materials), laboratory animals, and other causes which were not work-related. Occupational history as a medical doctor was asked in open-ended style. Work-related symptoms were defined based on the literature by one of the present authors (Kusaka et al. 1986). It was considered to be work-related if the symptoms appeared in the workplace and decreased or disappeared at home, the symptoms appeared on the days on duty (e.g. weekdays) and decreased or disappeared during the days off duty (e.g. weekends and holidays), and the symptoms disappeared after a change of the workplace or profession.

\section{Serological test}

Each April, from 1993 to 1996 and from 1999 to 2001, we conducted serological tests for the respondents of our baseline questionnaire. Specific IgE antibodies to mites (Anti-Dermatophagoides) and Japanese cedar (Anti-Cryptomeria pollen) in the blood serum were measured by CAP System. Results were given in $\mathrm{kU} / \mathrm{l}$ and subdivided into classes from zero to six. According to the literature (Pastorello et al. 1992; San Martín Ciges et al. 1998; Cantani 2008), CAP Class 0 is absent or undetectable $(<0.35 \mathrm{kU} / \mathrm{l})$, but the Class 1 is slightly elevated in terms of $\mathrm{kU} / \mathrm{l}(\geq 0.35$ and $<0.70 \mathrm{kU} / \mathrm{l}$ ); Class 1 was accurate threshold for atopy. Therefore, CAP Class $\geq 1$ was used as positive in the current study.

\section{Study population}

Baseline self-administered questionnaire survey and CAP test were performed on all 4th grade medical students enrolled at the School of Medicine, University of Fukui in every April from 1993 to 1996 and from 1999 to 2001. CAP test was conducted on the blood of the respondents to our baseline questionnaire. In total, of the 702 subjects, 548 (78.1\%, 352 men and 196 women) filled in the questionnaire. Of the 548 respondents, age was distributed 2140 years and mean age \pm SD was $23.2 \pm 2.9$. Current smokers were $86(24.4 \%)$ for men and $9(4.6 \%)$ for women, lower than results of The National Health and Nutrition Survey in Japan (Ministry of Health, Labour and Welfare of Japan, 2003) for Japanese general population of 2029 years (55.8\% for men and $19.0 \%$ for women). Of the
548 subjects who responded to the baseline questionnaire, 415 (75.7\%, 263 men and 152 women) had CAP test.

We compared the characteristics between participants and non-participants for the CAP test. With respect to gender, age, personal history of allergic diseases, and smoking status, there were no significant differences between both groups.

In May 2004, the follow-up questionnaires were sent by post to 548 subjects who had answered our baseline questionnaire. Based on the mail survey implementation procedure (Dillman 2000), an initial 'warm contact' letter and a business reply envelope were attached to a hard copy questionnaire. If necessary, next replacement questionnaire and a final reminder letter were subsequently sent over the next 4-8 weeks. Finally, 263/548 (48.0\%) were filled in and returned to us. Having excluded the respondents who had failed on the National Examination for Medical Practitioners, we evaluated 261 eligible respondents $(47.6 \%, 162$ men and 99 women, aged 24-44 years).

The response rates to follow-up questionnaire did not differ greatly (mean $\pm \mathrm{SD}$ was $37.5 \pm 6.7 \%$ ) among all students in each year's baseline questionnaire surveys. We compared the characteristics between respondents and nonrespondents to the follow-up study. With respect to gender, age, and personal history of allergic diseases, there were no significant differences between respondent and non-respondent group. Percentage of current or ex-smoker were significantly higher $(p=0.006)$ among non-respondents (29.3\%) than respondents (19.2\%). We also compared the characteristics between participants and non-participants for the CAP test among 261 eligible respondents for the follow-up survey and could not find out significant differences between both groups.

\section{Ethics}

Our study was conducted in accordance with the ethical approval from the Administrative Students Committee formed by educational staff and the Graduates' Association of the School of Medicine, University of Fukui, since ethics committee or institutional review board for ethics (IRB) was under reorganisation at the time in our university. Written informed consent was obtained before taking blood samples. The collected data were anonymised and kept securely to ensure personal data confidentiality.

\section{Statistical analysis}

The study variables were dichotomised for convenience: smoking status (never smoked and current or ex-smoker), frequency of prepared foods consumption (less than 3 times a week and more than 4 times a week). Profession of medical doctors was firstly classified into 16 categories listed 
below, based on current and/or longest-held job obtained from self-reported occupational history, then dichotomised into surgical (orthopaedics, surgery, neurosurgery, ophthalmology, anaesthesiology, urology, otorhinolaryngology, obstetrics and gynaecology, and emergency medicine) and non-surgical (internal medicine, radiology, paediatrics, dermatology, psychiatry, basic medicine, and doctorin-training).

Pearson's chi-square test was used to evaluate the associations between dichotomous variables. When an overall total of the contingency table was less than 20 , or the overall total was between 20 and 40 and the smallest expectation was less than five, we followed the recommendation about minimum expectations (Cochran 1954; Kirkwood and Sterne 2003), Fisher's exact test was used.

Univariate and multivariate logistic regression analysis were used to calculate crude and adjusted odds ratios (ORs). To meet the requirement that the number of outcomes per explanatory variables into the multivariate logistic regression models should be 10 or greater (Harrell et al. 1985; Peduzzi et al. 1996), with the exception of gender and age which were included in all models, we excluded the explanatory variables whose univariate $p$ values were greater than 0.250 ; thereafter, we also performed further selection of variables. Multicollinearity was evaluated by variance-covariance matrix. Multivariate logistic regression analysis was conducted with a backward elimination procedure at the $p=0.10$ significance level for removal from the model or a forward entry procedure based on maximum likelihood ratio. Adjusted OR and its $95 \%$ confidence interval $(95 \% \mathrm{CI})$ were calculated. Goodness of fit was assessed by the Hosmer-Lemeshow test. The level of statistical significance was set at 0.05 for all calculations. The statistical software package SPSS version $16.0 \mathrm{~J}$ for Windows (SPSS Inc., Chicago, IL, USA) was used to perform the analysis.

\section{Results}

Characteristics of respondents

Of the 261 respondents, age ranged from 24 to 44 years and mean age $\pm S D$ was $30.3 \pm 3.5$. Current and ex-smoker were $21(12.9 \%)$ and $29(17.8 \%)$ for men and $4(4.1 \%)$ and $4(4.1 \%)$ for women, respectively. Overall, $73(28.2 \%)$ were for surgical and $119(45.9 \%)$ were for the internal medicine profession, $2(0.8 \%)$ were for basic medicine, and $65(25.1 \%)$ were for doctors-in-training. Of the 261 subjects who responded to the follow-up questionnaire, 215 $(82.4 \%, 133$ men and 82 women) had participated serological test at baseline. The subjects with CAP positive were $113 / 215(52.6 \%)$ and $113 / 215(52.6 \%)$ for mites and
Japanese cedar, respectively, and both were strongly associated with each other $(p<0.001)$. Characteristics of respondents to the follow-up questionnaire are summarised in Table 1. CAP positivity and employment in the surgical profession were significantly associated with work-related allergy-like symptoms, by chi-square test.

Risk factors for baseline CAP positivity for mites and cedar

Multivariate logistic regression analyses conducted among eligible 210 follow-up subjects (Tables were not shown). CAP positivity for mites had a significant positive association with living in residential zone before becoming a medical student. CAP positivity for Japanese cedar was significantly associated with a family history of AR/PA and frequent consumption of prepared food at baseline study. Age, gender, and keeping domestic animals were not significant for specific IgE against house dust mites and cedar.

\section{Causes of work-related allergy-like symptoms}

As listed in Table 2, major causes of work-related allergylike symptoms in the working environment reported by respondents themselves were surgical gloves including latex gloves, powder of latex gloves, laboratory animals, and chemical substances, e.g. chlorhexidine gluconate solution, benzalkonium chloride, and povidone-iodine.

\section{Distribution of the subjects}

The proportion of medical doctors who answered 'yes' for history of allergy-like symptoms by work relation and those for work-related allergy-like symptoms by total work duration are summarised in Tables 3 and 4, respectively. The frequency of work-related respiratory symptoms was low among our study subjects and the symptoms appeared as long as 66 months after exposure. On the other hand, the work-related dermal symptoms were the most frequent among work-related allergy-like symptoms and were present after even short work duration of 2-3 months. Figure 1 schematically displays the distribution of follow-up subjects grouped by the presence or absence of any type of allergy-like symptoms and any type of work-related allergy-like symptoms, and changes in these symptoms' severity after graduation. Of 261 respondents of the followup study, 122 (46.7\%) had no history of allergy-like symptoms, whether work-related or not, $85(32.6 \%)$ only had history of allergy-like symptoms that were not workrelated, and $54(20.7 \%)$ had a history of any types of workrelated allergy-like symptoms. Among 54 work-related symptoms, with three respondents who had not filled in all questionnaire items excluded, 21/51 (41.2\%) were newly emerged and 14/51 (27.5\%) worsened after graduation. 
Table 1 Characteristics of 261 follow-up respondents by work-related allergy-like symptoms

\begin{tabular}{|c|c|c|c|c|}
\hline & No $(\%)$ & $\begin{array}{l}\text { Allergy-like symptoms } \\
\text { without work relation }(\%)\end{array}$ & $\begin{array}{l}\text { Work-related allergy-like } \\
\text { symptoms }(\%)\end{array}$ & $\chi^{2}, p$ \\
\hline \multicolumn{5}{|l|}{ Demographic information } \\
\hline \multicolumn{5}{|l|}{ Gender } \\
\hline Male & $82(50.6)$ & $53(32.7)$ & $27(16.7)$ & \multirow[t]{2}{*}{0.095} \\
\hline Female & $40(40.4)$ & $32(32.3)$ & $27(27.3)$ & \\
\hline \multicolumn{5}{|l|}{ Age (follow-up) } \\
\hline$<30$ & $39(40.6)$ & $37(38.5)$ & $20(20.8)$ & \multirow[t]{2}{*}{0.237} \\
\hline$\geq 30$ & $83(50.3)$ & $48(29.1)$ & $34(20.6)$ & \\
\hline \multicolumn{5}{|l|}{ History of allergic diseases (baseline) } \\
\hline \multicolumn{5}{|l|}{ Bronchial asthma } \\
\hline Yes & $6(25.0)$ & $10(41.7)$ & $8(33.3)$ & \multirow[t]{2}{*}{0.068} \\
\hline No & $116(48.9)$ & 75 (31.6) & $46(19.4)$ & \\
\hline \multicolumn{5}{|l|}{ Allergic rhinitis and/or pollen allergy } \\
\hline Yes & 19 (21.6) & $43(48.9)$ & $26(29.5)$ & \multirow[t]{2}{*}{$<0.001$} \\
\hline No & $103(59.5)$ & $42(24.3)$ & $28(16.2)$ & \\
\hline \multicolumn{5}{|l|}{ Atopic dermatitis } \\
\hline Yes & $6(21.4)$ & $10(35.7)$ & $12(42.9)$ & \multirow[t]{2}{*}{0.003} \\
\hline No & $116(50.0)$ & $74(31.9)$ & $42(18.1)$ & \\
\hline \multicolumn{5}{|l|}{ Lifestyle (baseline) } \\
\hline \multicolumn{5}{|l|}{ History of keeping domestic animals } \\
\hline Yes & $96(44.7)$ & $70(32.6)$ & $49(22.8)$ & \multirow[t]{2}{*}{0.183} \\
\hline No & $25(55.6)$ & $15(33.3)$ & $5(11.1)$ & \\
\hline \multicolumn{5}{|l|}{ Prepared foods consumption } \\
\hline$\leq 3$ times/week & $95(45.2)$ & $65(31.0)$ & $50(23.8)$ & \multirow[t]{2}{*}{0.056} \\
\hline$\geq 4$ times/week & $25(52.1)$ & 19 (39.6) & $4(8.3)$ & \\
\hline \multicolumn{5}{|l|}{ CAP test (baseline) } \\
\hline \multicolumn{5}{|l|}{ Mites } \\
\hline Class 0 & $58(56.9)$ & $30(29.4)$ & $14(13.7)$ & \multirow[t]{2}{*}{0.002} \\
\hline Class $\geq 1$ & $39(34.5)$ & $40(35.4)$ & $34(30.1)$ & \\
\hline \multicolumn{5}{|l|}{ Japanese cedar } \\
\hline Class 0 & $56(54.9)$ & $33(32.4)$ & $13(12.7)$ & \multirow[t]{2}{*}{0.002} \\
\hline Class $\geq 1$ & $41(36.3)$ & $37(32.7)$ & $35(31.0)$ & \\
\hline Lifestyle (follow-up) & & & & \\
\hline Smoking status & & & & \\
\hline Current and ex-smoker & $29(50.0)$ & $17(29.3)$ & $12(20.7)$ & 0.813 \\
\hline Never smoked & $93(46.0)$ & $68(33.7)$ & $41(20.3)$ & \\
\hline Occupational history (follow-up) & & & & \\
\hline Work duration & & & & \\
\hline$<12$ months & $23(50.0)$ & $18(39.1)$ & $5(10.9)$ & 0.215 \\
\hline $12 \leq x<24$ months & $9(29.0)$ & $14(45.2)$ & $8(25.8)$ & \\
\hline $24 \leq x<36$ months & $11(32.4)$ & $14(41.2)$ & $9(26.5)$ & \\
\hline $36 \leq x<72$ months & $19(54.3)$ & $8(22.9)$ & $8(22.9)$ & \\
\hline $72 \leq x<84$ months & $19(54.3)$ & $11(31.4)$ & $5(14.3)$ & \\
\hline $84 \leq x<96$ months & $21(50.0)$ & $13(31.0)$ & $8(19.0)$ & \\
\hline$\geq 96$ months & $17(53.1)$ & $6(18.8)$ & $9(28.1)$ & \\
\hline Profession & & & & \\
\hline Surgical & $40(54.8)$ & $14(19.2)$ & $19(26.0)$ & 0.027 \\
\hline Internal & $55(46.2)$ & $41(34.5)$ & $23(19.3)$ & \\
\hline Basic medicine and doctor-in-training & $27(40.3)$ & $30(44.8)$ & $10(14.9)$ & \\
\hline
\end{tabular}

Percentages in the parenthesis may not add up to $100 \%$ because of rounding 
Table 2 Causes of work-related allergy-like symptoms at follow-up study

\begin{tabular}{|c|c|c|c|c|}
\hline & Respiratory & Dermal & Nasal & Ocular \\
\hline Chemical substances, medical tools, and medical materials & 0 & 36 & 4 & 2 \\
\hline Ethanol & 0 & 3 & 1 & 0 \\
\hline Chlorhexidine gluconate solution (HIBITANE ${ }^{\circledR}$ ) & 0 & 4 & 0 & 0 \\
\hline Benzalkonium chloride (WELPAS ${ }^{\circledR}$ ) & 0 & 2 & 0 & 0 \\
\hline Povidone-iodine (Isodine ${ }^{\circledR}$ ) & 0 & 4 & 0 & 0 \\
\hline Formalin & 0 & 0 & 1 & 1 \\
\hline Chloroform & 0 & 1 & 0 & 0 \\
\hline Surgical gloves (including latex gloves) & 0 & 16 & 0 & 0 \\
\hline Powder of latex gloves & 0 & 4 & 1 & 0 \\
\hline Powder of plaster casts & 0 & 1 & 1 & 1 \\
\hline Ultraviolet for therapy & 0 & 1 & 0 & 0 \\
\hline Laboratory animals & 2 & 4 & 5 & 5 \\
\hline Mice & 1 & 2 & 3 & 2 \\
\hline Rats & 1 & 1 & 1 & 1 \\
\hline Rabbits & 0 & 1 & 1 & 1 \\
\hline Cats & 0 & 0 & 0 & 1 \\
\hline Other causes & 0 & 8 & 2 & 1 \\
\hline Hand washing for operation & 0 & 3 & 0 & 0 \\
\hline Working in the room for premature babies & 0 & 1 & 0 & 0 \\
\hline Mental stress & 0 & 1 & 0 & 0 \\
\hline Lack of sleep & 0 & 2 & 0 & 0 \\
\hline Sweat & 0 & 1 & 0 & 0 \\
\hline Tobacco smoke in a psychiatric ward & 0 & 0 & 1 & 0 \\
\hline Air pollutants in visiting patients & 0 & 0 & 1 & 0 \\
\hline Pollen of Japanese cedar near working place & 0 & 0 & 0 & 1 \\
\hline
\end{tabular}

Table 3 Allergy-like symptoms at follow-up study by their work relation

\begin{tabular}{lllc}
\hline & No $(\%)$ & $\begin{array}{l}\text { Yes: without } \\
\text { work } \\
\text { relation }(\%)\end{array}$ & $\begin{array}{l}\text { Yes: with } \\
\text { work } \\
\text { relation }(\%)\end{array}$ \\
\hline Respiratory symptoms & $238(91.2)$ & $19(7.3)$ & $4(1.5)$ \\
Dermal symptoms & $193(73.9)$ & $27(10.3)$ & $41(15.7)$ \\
Nasal symptoms & $160(61.3)$ & $85(32.6)$ & $16(6.1)$ \\
$\begin{array}{l}\text { Ocular symptoms } \\
\text { Any allergy-like }\end{array}$ & $206(78.9)$ & $47(18.0)$ & $8(3.1)$ \\
\multicolumn{1}{c}{ symptoms } & $122(46.7)$ & $85(32.6)$ & $54(20.7)$ \\
\hline
\end{tabular}

Percentages in the parenthesis may not add up to $100 \%$ because of rounding

Whereas among 85 having allergic symptoms not workrelated, with three respondents who had not filled in all questionnaire items excluded, 54/82 (65.9\%) had symptoms unchanged and 10/82 (12.2\%) had remission of symptoms or none after graduation. Figure 2 shows the number of respondents with and without a history of work-related allergy-like symptoms grouped by the follow-up period after graduation; since new recruitment of subjects for the baseline study was not conducted in 1997 and 1998, the number of respondents to follow-up questionnaire was few as to the corresponding follow-up period, 4 and 5 years. The percentage of work-related allergy-like symptoms rose within the first 2-3 years of their career and reached a plateau after that; respondents with a history of work-related allergy-like symptoms were $10.9 \%$ among medical doctors at 6 months follow-up and were up to $25.8 \%$, virtually a plateau, among the 18-month follow-up population.

Risk factors for allergy-like symptoms and work-related allergy-like symptoms

The association between history of any allergy-like symptoms at follow-up for relevant baseline and follow-up items was evaluated by univariate and multivariate logistic regression analysis with a backward elimination procedure based on maximum likelihood ratio. Excluding 62 respondents, who inconsistently answered 'yes' at baseline but 'no' at follow-up to the same question on history of any allergy-like symptoms and anyone with missing values for the explanatory variables, we analysed 186 respondents. The crude and adjusted ORs and $p$ value are shown in Table 5. 
Table 4 Number of respondents $(\%)$ with work-related allergy-like symptoms at follow-up study grouped by work duration

${ }^{a}$ A respondent with allergy-like symptoms in multiple organs is considered as a caput

\begin{tabular}{lclcc}
\hline Work duration & Months $<12$ & $12 \leq$ months $<24$ & $24 \leq$ months $<36$ & $36 \leq$ months \\
\hline All respondents & $46(100.0)$ & $31(100.0)$ & $34(100.0)$ & $144(100.0)$ \\
Respiratory symptoms (\%) & $0(0.0)$ & $0(0.0)$ & $0(0.0)$ & $4(2.8)$ \\
Dermal symptoms (\%) & $4(8.7)$ & $7(22.6)$ & $9(26.5)$ & $20(13.9)$ \\
Nasal symptoms (\%) & $0(0.0)$ & $1(3.2)$ & $2(5.9)$ & $12(8.3)$ \\
Ocular symptoms (\%) & $1(2.2)$ & $0(0.0)$ & $1(2.9)$ & $6(4.2)$ \\
Any work-related & $5(10.9)$ & $8(25.8)$ & $9(26.5)$ & $30(20.8)$ \\
$\quad$ allergy-like symptoms & & & \\
\hline
\end{tabular}

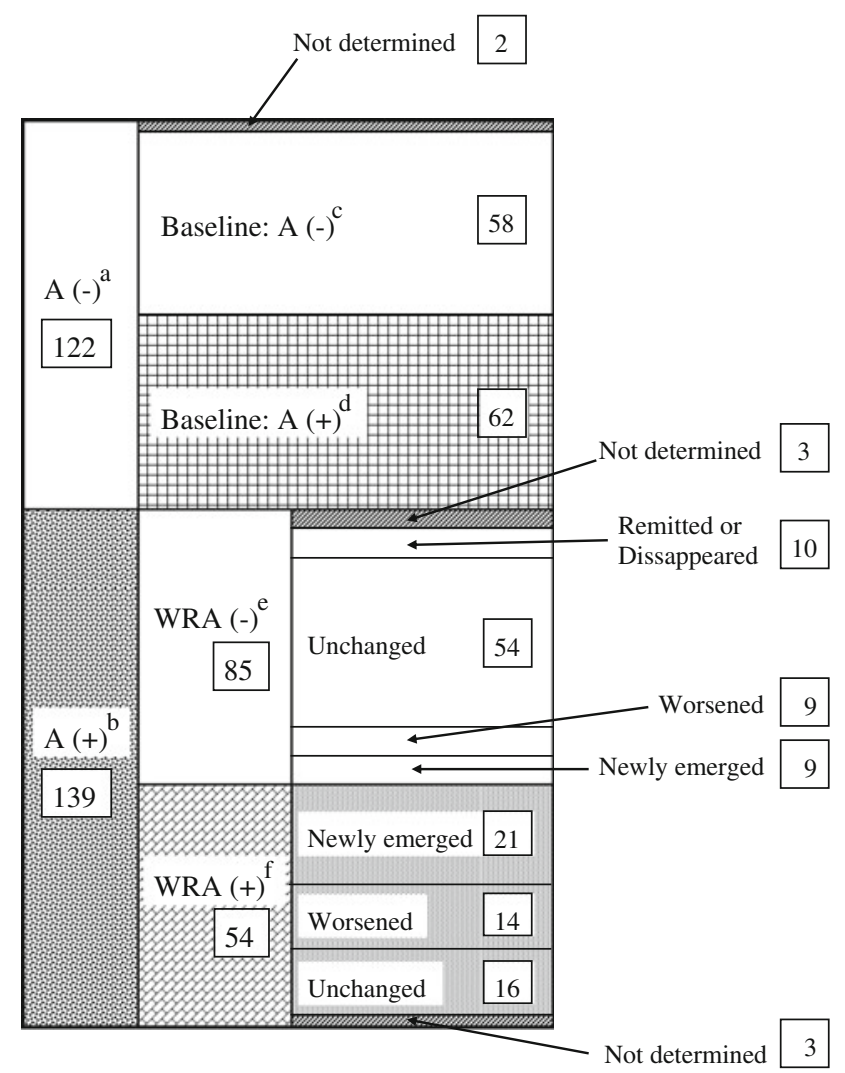

Fig. 1 Distribution of follow-up subjects grouped by the presence or absence of any type of allergy-like symptoms and any type of workrelated allergy-like symptoms and changes in these symptoms' severity after graduation. The number of subjects for each group is denoted in the square. ${ }^{a}$ absence of any type of allergy-like symptoms at followup study ${ }^{b}$ presence of any type of allergy-like symptoms at follow-up study ${ }^{c}$ absence of any type of allergy-like symptoms at baseline study ${ }^{d}$ presence of any type of allergy-like symptoms at baseline study ${ }^{e}$ absence of any type of work-related allergy-like symptoms at followup study ${ }^{\mathrm{f}}$ presence of any type of work-related allergy-like symptoms at follow-up study

The association between history of any work-related allergy-like symptoms for relevant baseline and follow-up items was evaluated in the same way. The analysis results for 153 respondents are shown in Table 6 . Table 7 summarises the descriptive statistics on the two groups of respondents for analysis and for exclusion in the multivariate

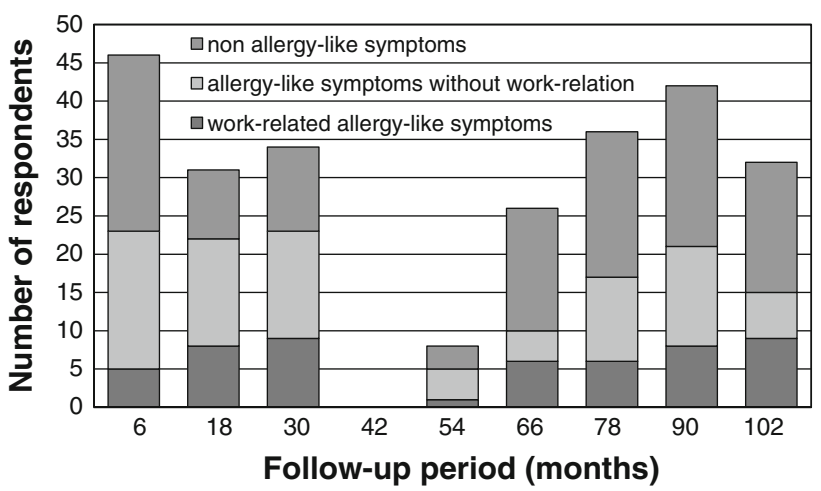

Fig. 2 Number of respondents with history of work-related allergylike symptoms, allergy-like symptoms without work relation, and nonallergy-like symptoms according to follow-up period

logistic regression analysis for work-related allergy-like symptoms. Compared with the analysis group, the exclusion group had significantly more frequent consumption of prepared foods $(p=0.035)$. There were no significant differences between two groups with respect to gender, age, personal history of atopy (BA, AR/PA, or AD), or smoking status.

\section{Discussion}

The goal of this study was to assess the risk factors associated with work-related allergy-like symptoms in medical doctors and supplied three major findings.

Firstly, we found prevalence of work-related allergy-like symptoms among doctors; 54 (20.7\%) of 261 doctors experienced any work-related allergy-like symptoms, workrelated respiratory allergy-like symptom was very few in the number, and work-related dermal allergy-like symptoms represented the vast majority of all types of workrelated symptoms. Some cases of work-related dermal symptoms, e.g. caused by hand washing in the operating theatre, from ethanol, povidone-iodine, surgical gloves, and powder of latex gloves, may be considered to be not allergy but irritation. Even if the prevalence of work-related dermal 
Table 5 Odds ratios for any allergy-like symptoms at follow-up of gender and family history of allergic diseases at baseline

\begin{tabular}{lllll}
\hline Variables & \multicolumn{2}{l}{ Any allergy-like symptoms at follow-up $(n=186)$} & & \\
\cline { 2 - 4 } & Yes $(\%)$ & Univariate OR (95\% CI) & $p$ & Multivariate OR (95\% CI) $^{\mathrm{a}}$ \\
\hline Gender & & 0.002 & 1.00 \\
Male & $73(61.9)$ & 1.00 & & $2.65(1.23-5.69)$ \\
Female & $57(83.8)$ & $3.19(1.52-6.73)$ & 0.002 & $2.31(1.17-4.56)$ \\
Family history of $\mathrm{BA}^{\mathrm{b}}, \mathrm{AR}^{\mathrm{c}} / \mathrm{PA}^{\mathrm{d}}$, and/or AD & \\
Yes & $74(80.4)$ & $2.79(1.44-5.40)$ & & 1.00 \\
No & $56(59.6)$ & 1.00 &
\end{tabular}

${ }^{a}$ Adjusted for gender, family history of allergic diseases, and lifestyle at baseline study, and age at follow-up study

b Bronchial asthma

c Allergic rhinitis

${ }^{\mathrm{d}}$ Pollen allergy

e Atopic dermatitis

Table 6 Odds ratios for any work-related allergy-like symptoms of personal history of allergic diseases, domestic animals, prepared foods consumption, eczema induced by common chemicals, and occupational history in medical doctors

\begin{tabular}{|c|c|c|c|c|c|}
\hline \multirow[t]{2}{*}{ Variables } & \multicolumn{5}{|c|}{ Any work-related allergy-like symptoms at follow-up study $(n=153)$} \\
\hline & Yes $(\%)$ & Univariate OR (95\% CI) & $p$ & Multivariate OR $(95 \% \mathrm{CI})^{\mathrm{a}}$ & $p$ \\
\hline \multicolumn{6}{|c|}{ Personal history of $\mathrm{BA}^{\mathrm{b}}, \mathrm{AR}^{\mathrm{c}} / \mathrm{PA}^{\mathrm{d}}$, and/or $\mathrm{AD}^{\mathrm{e}}$ (baseline) } \\
\hline Yes & $28(40.6)$ & $2.50(1.23-5.09)$ & 0.010 & $2.30(1.07-4.97)$ & 0.034 \\
\hline No & $18(21.4)$ & 1.00 & & 1.00 & \\
\hline \multicolumn{6}{|c|}{ Domestic animals (baseline) } \\
\hline Yes & $41(33.6)$ & $2.63(0.94-7.36)$ & 0.058 & $3.06(1.01-9.27)$ & 0.048 \\
\hline No & $5(16.1)$ & 1.00 & & 1.00 & \\
\hline \multicolumn{6}{|c|}{ Prepared foods consumption (baseline) } \\
\hline$\leq 3$ times/week & $43(32.8)$ & $3.10(0.87-10.99)$ & 0.069 & $4.35(1.08-17.62)$ & 0.039 \\
\hline$\geq 4$ times/week & $3(13.6)$ & 1.00 & & 1.00 & \\
\hline \multicolumn{6}{|c|}{ Eczema induced by rubber gloves, metallic accessories, and/or cosmetics (baseline) } \\
\hline Yes & $23(47.9)$ & $3.28(1.58-6.81)$ & $<0.001$ & $3.36(1.52-7.42)$ & 0.003 \\
\hline No & $23(21.9)$ & 1.00 & & 1.00 & \\
\hline \multicolumn{6}{|c|}{ Profession (follow-up) } \\
\hline Surgical & $17(43.6)$ & $2.26(1.06-4.85)$ & 0.033 & $2.71(1.17-6.32)$ & 0.021 \\
\hline Non-surgical & $29(25.4)$ & 1.00 & & 1.00 & \\
\hline
\end{tabular}

a Adjusted for gender, personal history of allergic diseases, and lifestyle at baseline study, and age and profession at follow-up study

b Bronchial asthma

c Allergic rhinitis

${ }^{d}$ Pollen allergy

e Atopic dermatitis

allergy-like symptoms may be overestimated for this reason, dermal symptoms would still be the most frequent type among work-related symptoms. The prevalence of workrelated respiratory allergy-like symptoms was the lowest among all types and the major cause being exposure to laboratory animal. All doctors with these symptoms were observed in the respondents' group after more than 5 years work. In addition, while nasal and ocular allergy-like symp- toms without work-relatedness were frequently observed among all types of allergy-like symptoms in our study; these work-related types were not as frequent as the workrelated dermal type. Since environmental pollen allergy and common rhinitis are usually seen in Japan, these may overlap the doctors' work-related nasal and ocular allergy-like symptoms. Or, as reported about occupational allergies developing after 2-3 years of exposure to laboratory animals 
Table 7 Comparison of characteristics between included respondents and excluded respondents in the follow-up multivariate analysis for workrelated allergy-like symptoms

\begin{tabular}{|c|c|c|c|c|}
\hline \multirow{2}{*}{ Variables } & \multirow[t]{2}{*}{$n$} & \multicolumn{2}{|c|}{ Multivariate analysis } & \multirow{2}{*}{$p$ value } \\
\hline & & Included (\%) & Excluded (\%) & \\
\hline Gender & 261 & & & 0.304 \\
\hline Male & & $91(59.5)$ & $71(65.7)$ & \\
\hline Female & & $62(40.5)$ & $37(34.3)$ & \\
\hline Age (follow-up) & 261 & & & 0.943 \\
\hline$<30$ & & $56(36.6)$ & $40(37.0)$ & \\
\hline$\geq 30$ & & $97(63.4)$ & $68(63.0)$ & \\
\hline Baseline study & 261 & & & 0.850 \\
\hline 1993 & & $24(15.7)$ & $18(16.7)$ & \\
\hline 1994 & & $27(17.6)$ & $16(14.8)$ & \\
\hline 1995 & & $18(11.8)$ & $18(16.7)$ & \\
\hline 1996 & & $16(10.5)$ & $12(11.1)$ & \\
\hline 1999 & & $26(17.0)$ & $13(12.0)$ & \\
\hline 2000 & & $22(14.4)$ & $15(13.9)$ & \\
\hline 2001 & & $20(13.1)$ & $16(14.8)$ & \\
\hline History of $\mathrm{BA}^{\mathrm{a}}, \mathrm{AR} \mathrm{PA}^{\mathrm{b}}, \mathrm{AD}^{\mathrm{c}}$ (baseline) & 261 & & & 0.193 \\
\hline Yes & & $69(45.1)$ & $40(37.0)$ & \\
\hline No & & $84(54.9)$ & $68(63.0)$ & \\
\hline $\begin{array}{l}\text { History of eczema caused by rubber gloves, } \\
\text { metallic accessories, cosmetics (baseline) }\end{array}$ & 209 & & & 0.726 \\
\hline Yes & & $48(31.4)$ & $19(33.9)$ & \\
\hline No & & $105(68.6)$ & $37(66.1)$ & \\
\hline Domestic animals (baseline) & 260 & & & 0.132 \\
\hline Yes & & $122(79.7)$ & $93(86.9)$ & \\
\hline No & & $31(20.3)$ & $14(13.1)$ & \\
\hline Prepared foods consumption (baseline) & 258 & & & 0.035 \\
\hline$\leq 3$ times/week & & $131(85.6)$ & $79(75.2)$ & \\
\hline$\geq 4$ times/week & & $22(14.4)$ & $26(24.8)$ & \\
\hline Smoking status (follow-up) & 260 & & & 0.784 \\
\hline Never smoked & & $119(78.3)$ & $83(76.9)$ & \\
\hline Ex-smoker and current smoker & & $33(21.7)$ & $25(23.1)$ & \\
\hline Work duration (follow-up) & 255 & & & 0.595 \\
\hline$<12$ month & & $26(17.0)$ & $20(19.6)$ & \\
\hline$\geq 12$ month & & $127(83.0)$ & $82(80.4)$ & \\
\hline Profession (follow-up) & 259 & & & 0.247 \\
\hline Surgical & & $39(25.5)$ & $34(32.1)$ & \\
\hline Non-surgical & & $114(74.5)$ & $72(67.9)$ & \\
\hline
\end{tabular}

Percentages in the parenthesis may not add up to $100 \%$ because of rounding

${ }^{\text {a }}$ Bronchial asthma

${ }^{b}$ Allergic rhinitis and/or pollen allergy

c Atopic dermatitis between family history of atopic diseases (BA, AR/PA, or $\mathrm{AD)}$ at baseline study and allergy-like symptoms.

Thirdly, we found several significant positive and inverse associations between any types of work-related allergy-like symptoms (respiratory, dermal, nasal, and ocular symptoms) and the baseline and follow-up questionnaire items. After adjustment, work-related allergy-like symptoms were significantly related to personal history of atopic diseases (BA, AR/PA, or AD) at baseline study. This strongly suggests that atopy is a concrete predictor of work- 
related allergy-like symptoms. In addition, the significant association between CAP positivity for mites and Japanese cedar and work-related allergy-like symptoms supports this finding.

We found that the history of eczema caused by rubber gloves, metallic accessories, e.g. earrings and wrist watches, and cosmetics, such as shampoos, soaps, hairdressings, and so on, in the baseline study lead to work-related allergy-like symptoms. Our subjects of baseline study were 4th grade medical students, and they had already been exposed to surgical gloves allergen and a variety of chemical substances during the experiments of medical school classes and the practice of human anatomy, besides allergens in daily use goods. In Japan, it was legally enacted in 1999 to provide the information about risks of latex allergy for users through the accompanying documents of medical materials. Before 1999, a great deal of latex gloves circulated on the market. It seems that part of our study population started to use latex gloves from their junior high school or high school days. About two-thirds of follow-up respondents have already worked as medical doctors on 1999 and have been exposed to latex in the work place. In addition, it was possible that remaining one-third of follow-up respondents have also been occupationally exposed to latex after 1999. In 2006, the guideline for safety measures to latex allergy was laid down for health care workers, patients, and allied company's workers. In addition, cosmetic products contain many allergens such as para-phenylenediamine (PPD), preservatives, fragrance mix, and formaldehyde (Laguna et al. 2009). Therefore, based on pre-existing sensitisation to these allergens, the work-related allergies may frequently appear among doctors exposed to one or several allergens in the work environment.

Employment in the surgical profession was significantly associated with work-related allergy-like symptoms. This finding coincides with the result of our previous cross-sectional study (Sato et al. 2004) conducted in another population of doctors.

There was no association between work-related allergylike symptoms and gender, age, or total work duration. Female gender was significantly associated with workrelated allergy-like symptoms $(\mathrm{OR}=2.25, p=0.022)$ in the univariate analysis, but this association disappeared after adjusting, implying the existence of confounders. Work duration was not significant either in univariate or multivariate models. In our descriptive analysis, the percentage of doctors with work-related symptoms rose within the first 2 3 years of their career and reached a plateau after that. Partly, this insignificant association seems to be come from a small number of the respondents with work-related allergy-like symptoms, or alternatively, there might be a plateau present in the incidence increase of work-related allergy-like symptoms.
Our study has some limitations. Firstly, since this was a questionnaire-based study, all the data concerning the medical history were founded on self-reported contents. Since the findings can be perceived to be advantageously to the study population, the quality of answers in terms of accuracy was expected to be uniformly higher than general population.

Secondly, the response rate to the follow-up questionnaire was low $(48.0 \%)$, despite the replacement questionnaires and reminder letters. The possible reasons are that doctors are busy and tend to change address frequently. Compared with the respondents, a percentage of current or ex-smoker of non-respondents was significantly higher. For this reason, smoking status might not be related to workrelated allergy-like symptoms in our results. With respect to other variables, there were no significant differences between the respondent group and the non-respondent group. Thus, 'loss to follow-up' bias is likely minimal.

Thirdly, many respondents were excluded from the current multivariate logistic regression analysis due to inconsistent and/or incomplete answers to the follow-up questionnaire. Therefore, our results might be affected by the recall bias. With respect to variables, gender, age, smoking status, profession, personal history of allergic diseases, and so on, there were no significant differences between the included group and the excluded group. Therefore, selection bias, such as responding tendency of doctors who were interested in allergies, is minimal.

Finally, the respondents with long work duration were few in number. Among eligible respondents, 65 of 259 (25.1\%) were doctor-in-training and 111 of 255 (43.5\%) were with less than 3 years of experience. We assume that this partly leads to a comparatively low prevalence of work-related allergy-like symptoms as a whole.

\section{Conclusion}

The present study provides new information on the risk factors associated with work-related allergy-like symptoms in medical doctors. We shed light on the significant associations between work-related allergy-like symptoms and atopy, personal history of eczema caused by common goods, history of keeping domestic animals, and employment in the surgical profession. Thorough risk management is warranted for doctors in the medical work place, in living environment, and their lifestyle from school days. With respect to prepared food consumption, an inverse association was found with work-related allergy-like symptoms.

Acknowledgments The authors are grateful to all participants for their cooperation. We also thank the secretariat of the Graduates' Association of Faculty of Medical Sciences, University of Fukui (Dr N Honda, the president) for helping us with mailing the follow-up questionnaires 
and Ms K Yamada and Mr Y Yamamoto, student affairs division, University of Fukui, for their clerical supports on data acquisition. Parts of this paper had been presented at the 29th International Congress on Occupational Health (Cape Town, South Africa, from 22nd to 27th March 2009), the 82nd Annual Meeting of Japan Society for Occupational Health (Fukuoka, Japan, from 20th to 22nd May 2009), the 83rd Annual Meeting of Japan Society for Occupational Health (Fukui, Japan, from 26th to 28th May 2010), and the 20th Asian Conference on Occupational Health (Bangkok, Thailand, from 9th to 11th March 2011).

\section{Conflict of interest None.}

Open Access This article is distributed under the terms of the Creative Commons Attribution Noncommercial License which permits any noncommercial use, distribution, and reproduction in any medium, provided the original author(s) and source are credited.

\section{References}

Arif AA, Delclos GL, Serra C (2009) Occupational exposures and asthma among nursing professionals. Occup Environ Med 66:274-278. doi:10.1136/oem.2008.042382

Cantani A (2008) Pediatric allergy, asthma and immunology. Springer, Berlin

Cochran WG (1954) Some methods for strengthening the common $\chi^{2}$ tests. Biometrics 10:417-451

Crippa M, Pasolini G (1997) Allergic reactions due to glove-lubricantpowder in health-care workers. Int Arch Occup Environ Health 70:399-402

Delclos GL, Gimeno D, Arif AA, Burau KD, Carson A, Lusk C, Stock T, Symanski E, Whitehead LW, Zock JP, Benavides FG, Antó JM (2007) Occupational risk factors and asthma among health care professionals. Am J Respir Crit Care Med 175:667-675. doi:10.1164/rccm.200609-13310C

Devereux G (2006) The increase in the prevalence of asthma and allergy: food for thought. Nat Rev Immunol 6:869-874

Dillman DA (2000) Mail and internet surveys, 2nd edn. Wiley, New York

Filon FL, Radman G (2006) Latex allergy: a follow up study of 1040 healthcare workers. Occup Environ Med 63:121-125. doi:10.1136/oem.2003.011460

Fuortes LJ, Weih L, Jones ML, Burmeister LF, Thorne PS, Pollen S, Merchant JA (1996) Epidemiologic assessment of laboratory animal allergy among university employees. Am J Ind Med 29:6774

Gautrin D, Ghezzo H, Infante-Rivard C, Malo JL (2001) Natural history of sensitization, symptoms and occupational diseases in apprentices exposed to laboratory animals. Eur Respir J 17:904908

Harrell FE Jr, Lee KL, Matchar DB, Reichert TA (1985) Regression models for prognostic prediction: advantages, problems, and suggested solutions. Cancer Treat Rep 69:1071-1077

ISAAC Co-ordinating Committee (1992) Manual for the international study of asthma and allergies in childhood (ISAAC). Bochum and Auckland

Kirkwood BR, Sterne JAC (2003) Essential medical statistics, 2nd edn. Blackwell, London

Kujala VM, Karvonen J, Läärä E, Kanerva L, Estlander T, Reijula KE (1997) Postal questionnaire study of disability associated with latex allergy among health care workers in Finland. Am J Ind Med 32:197-204

Kusaka Y, Yokoyama K, Sera Y, Yamamoto S, Sone S, Kyono H, Shirakawa T, Goto S (1986) Respiratory diseases in hard metal workers: an occupational hygiene study in a factory. Br J Ind Med 43:474-485

Lagier F, Vervloet D, Lhermet I, Poyen D, Charpin D (1992) Prevalence of latex allergy in operating room nurses. J Allergy Clin Immunol 90:319-322

Laguna C, de la Cuadra J, Martín-González B, Zaragoza V, MartínezCasimiro L, Alegre V (2009) Allergic contact dermatitis to cosmetics. [Article in Spanish] Actas Dermosifiliogr 100:53-60

Larese Firon F, Bosco A, Fiorito A, Negro C, Barbina P (2001) Latex symptoms and sensitisation in health care workers. Int Arch Occup Environ Health 74:219-223

Leggat PA, Smith DR (2007) Hand dermatitis among medical students from north Queensland, Australia. Contact Dermat 56:137-139

Leung R, Ho A, Chan J, Choy D, Lai CK (1997) Prevalence of latex allergy in hospital staff in Hong Kong. Clin Exp Allergy 27:167174

Liss GM, Sussman GL, Deal K, Brown S, Cividino M, Siu S, Beezhold DH, Smith G, Swanson MC, Yunginger J, Douglas A, Holness DL, Lebert P, Keith P, Wasserman S, Turjanmaa K (1997) Latex allergy: epidemiological study of 1351 hospital workers. Occup Environ Med 54:335-342

Lundbäck B (1998) Epidemiology of rhinitis and asthma. Clin Exp Allergy 28:3-10

Ministry of Health, Labour and Welfare of Japan (2003) The national health and nutrition survey in Japan, 2003. [in Japanese] Daiichishuppan, Tokyo

Mirabelli MC, Zock JP, Plana E, Antó JM, Benke G, Blanc PD, Dahlman-Höglund A, Jarvis DL, Kromhout H, Lillienberg L, Norbäck D, Olivieri M, Radon K, Sunyer J, Torén K, van Sprundel M, Villani S, Kogevinas M (2007) Occupational risk factors for asthma among nurses and related healthcare professionals in an international study. Occup Environ Med 64:474-479. doi:10.1136/ oem.2006.031203

Nettis E, Assennato G, Ferrannini A, Tursi A (2002) Type I allergy to natural rubber latex and type IV allergy to rubber chemicals in health care workers with glove-related skin symptoms. Clin Exp Allergy 32:441-447

Ng TP, Tan WC (1994) Epidemiology of allergic rhinitis and its associated risk factors in Singapore. Int J Epidemiol 23:553-558

Norbäck D, Zhao ZH, Wang ZH, Wieslander G, Mi YH, Zhang Z (2007) Asthma, eczema, and reports on pollen and cat allergy among pupils in Shanxi province, China. Int Arch Occup Environ Health 80:207-216. doi:10.1007/s00420-006-0123-6

Ogino S, Irifune M, Harada T, Matsunaga T, Ishida M (1990) Nasal allergy in medical students. Rhinology 28:163-168

Pastorello EA, Incorvaia C, Pravettoni V, Marelli A, Farioli L, Ghezzi M (1992) Clinical evaluation of CAP System and RAST in the measurement of specific IgE. Allergy 47:463-466

Pearce N, Weiland S, Keil U, Langridge P, Anderson HR, Strachan D, Bauman A, Young L, Gluyas P, Ruffin D, Crane J, Beasley R (1993) Self-reported prevalence of asthma symptoms in children in Australia, England, Germany and New Zealand: an international comparison using the ISAAC protocol. Eur Respir J 6:1455-1461

Pechter E, Davis LK, Tumpowsky C, Flattery J, Harrison R, Reinisch F, Reilly MJ, Rosenman KD, Schill DP, Valiante D, Filios M (2005) Work-related asthma among health care workers: surveillance data from California, Massachusetts, Michigan, and New Jersey, 1993-1997. Am J Ind Med 47:265-275

Peduzzi P, Concato J, Kemper E, Holford TR, Feinstein AR (1996) A simulation study of the number of events per variable in logistic regression analysis. J Clin Epidemiol 49:1373-1379

Ronchetti R, Villa MP, Barreto M, Rota R, Pagani J, Martella S, Falasca C, Paggi B, Guglielmi F, Ciofetta G (2001) Is the increase in childhood asthma coming to an end? Findings from three surveys of schoolchildren in Rome, Italy. Eur Respir J 17:881-886 
San Martín Ciges E, Chesa-Jiménez J, Sanmartín Gil M, Ruiz Hernández G, Moreno Frígols JL (1998) Estudio de la relación entre la concentración plasmática total de IgE y la prevalencia de las distintas clases RAST (Radio-Allergo-Sorbent-Test) de alergia. [Article in Spanish] Allergol Immunopathol (Madr) 26:228-233

Sato K, Kusaka Y, Suganuma N, Nagasawa S, Deguchi Y (2004) Occupational allergy in medical doctors. J Occup Health 46:165-170

Taylor B, Broom BC (1981) Atopy in medical students. Ann Allergy 47:197-199

Vandenplas O, Delwiche JP, Evrard G, Aimont P, van der Brempt X, Jamart J, Delaunois L (1995) Prevalence of occupational asthma due to latex among hospital personnel. Am J Respir Crit Care Med 151:54-60

Verna N, Di Giampaolo L, Renzetti A, Balatsinou L, Di Stefano F, Di Gioacchino G, Di Rocco P, Schiavone C, Boscolo P, Di Gioacchino M (2003) Prevalence and risk factors for latex-related diseases among healthcare workers in an Italian general hospital. Ann Clin Lab Sci 33:184-191

Zöllner IK, Weiland SK, Piechotowski I, Gabrio T, von Mutius E, Link B, Pfaff G, Kouros B, Wuthe J (2005) No increase in the prevalence of asthma, allergies, and atopic sensitisation among children in Germany: 1992-2001. Thorax 60:545-548 